\title{
PELATIHAN PENGELOLAAN WEBSITE SEBAGAI UPAYA MENINGKATKAN PUBLIKASI PROFIL KELURAHAN TANGKERANG SELATAN PEKANBARU
}

\author{
Regiolina Hayami*, Soni, Yulia Fatma, Febby Apri Wenando \\ Prodi Teknik Informatika, Fakultas Ilmu Komputer \\ Universitas Muhammadiyah Riau \\ email: regiolinahayami@umri.ac.id
}

\begin{abstract}
Website is one of the internet media tools that functions to display, promote and can even be used as a media to find information needed quickly and without space and time. Kelurahan as one of the government institutions requires media interaction and socialization so that people both living in the region and the wider community can get all information relating to the region quickly. With a website it can be easy to access and become a media of information to be more effective and efficient because it can be accessed anywhere and anytime. This community service aims to provide learning education in the form of training on website management as a profile information on the Tangkerang Selatan village profile. With this community service, it is expected to be able to help the village in helping and using blogspot as a media for publication of profiles and information in the Tangkerang Selatan village.
\end{abstract}

Keywords: Website Profile, Blogspot, Community Service, Tangkerang Selatan Village

\begin{abstract}
Abstrak
Website merupakan salah satu sarana media internet yang berfungsi untuk menampilkan, memperkenalkan bahkan dapat berfungsi sebagai media pencari informasi yang sedang dibutuhkan dengan cepat dan tanpa batasan ruang dan waktu. Kelurahan sebagai salah satu lembaga pemerintahan membutuhkan media interaksi dan sosialisasi agar masyarakat baik yang tinggal diwilayah tersebut maupun masyarakat luas dapat memperoleh segala informasi terkait wilayah dengan cepat. Dengan adanya website dapat mempermudah dalam pengaksesan serta menjadi media informasi menjadi lebih efektif dan efisien karena dapat diakses dimanapun dan kapanpun. Pengabdian masyarakat ini bertujuan untuk memberikan edukasi pembelajaran dalam bentuk pelatihan tentang pengelolaan website sebagai media informasi profil kelurahan Tangkerang Selatan. Dengan adanya pengabdian masyarakat ini diharapkan dapat membantu pihak kelurahan dalam memanfaatkan dan menerapkan blogspot sebagai media publikasi profil dan informasi di kelurahan Tangkerang Selatan.
\end{abstract}

Kata Kunci : Website Profil, Blogspot, Pengabdian, Kelurahan Tangkerang Selatan

\section{PENDAHULUAN}

Salah satu media penyampaian informasi suatu perusahaan atau instansi pemerintah adalah website company profile. Website company profile adalah sebuah website yang menampilkan informasi tentang latar belakang sebuah perusahaan, produk atau layanan, informasi kontak dan berita singkat seputar perusahaan.

Perkembangan tentang informasi dan teknologi sangat penting mengingat setiap tahun atau bahkan setiap bulan ilmu pengetahuan dan informasi selalu berkembang. Sebagai akibat dari perkembangan teknologi ini membuat kelurahan sebagai salahsatu lembaga 
pemerintahan harus dapat mengikuti perkembangan tersebut agar tidak tertinggal dalam upaya penyampaian informasi. Penyampaian informasi yang selama ini digunakan kebanyakan menggunakan cara konvensional. Cara konvensional tersebut antara lain penyampaian informasi ataupun kegiatan yang dilaksanakan di wilayah kelurahan masih menggunakan media spanduk, papan pengumuman dan media massa. Selain itu jika masyarakat luas ingin mengetahui informasi terkait profil dari wilayah kelurahan masih dirasa kurang efektif karena kurangnya update informasi dilaman internet. Dengan penyebaran informasi yang demikian dirasakan masih memiliki banyak kekurangan, antara lain jangkauan penyebaran informasinya yang masih kurang luas, muatan informasi yang terbatas, proses update informasi yang kurang menguntungkan baik menyangkut biaya maupun waktu.

Salah satu alamat situs yang dapat dijadikan sebagai media informasi dan dengan mudah dapat dipelajari adalah aplikasi Blog atau Weblog. Melalui Blog data-data, informasi, pengetahuan, bahkan hal-hal yang sifatnya promosi dapat disajikan dengan cara memasukkan data tersebut pada aplikasi, selanjutnya data dapat diakses oleh masyarakat luas atau pengunjung yang membutuhkan informasi tersebut.

Web Blog merupakan sarana penyampaian secara online yang memiliki fasilitas dasar internet yang mampu menembus batas ruang dan waktu. Blog juga merupakan media yang sangat interaktif dan media yang sangat dinamis untuk membahas wawasan dan eksistensi diri. Blog dapat pula juga disebut sebgai media digital yang komunitas elektroniknya bertebaran di internet dan dengan sekian banyaknya Blog di internet yang selalu mencari Website yang menarik maka akan membuat blok semakin unik saja.
Blog mempunyai fungsi sangat beragam, dari sebuah catatan harian sampai dengan media publikasi dan penyedia fasilitas interaksi dengan para pengunjungnya. Walaupun Web Blog memiliki fitur yang cukup lengkap, namun sayangnya hingga saat ini masih banyak pegawai di kelurahan yang belum mengetahui mengenai Blog tersebut. Oleh karena itu, perlu dilaksanakan kegiatan pengabdian mengenai pelatihan pengelolaan website sebagai upaya meningkatkan publikasi profil yang dilaksanakan di Kantor Lurah Tangkerang Selatan Pekanbaru.

\section{METODE PENGABDIAN}

Berdasarkan permasalahan yang telah diuraikan sebelumnya, maka kerangka pencapaian solusi yang ditawarkan adalah Memberikan sosialiasi kepada seluruh pegawai yang ada di kantor lurah Tangkerang Selatan tentang tata cara penggunaan Blogspot.

Diharapkan Setiap pegawai kelurahan dapat menggunakan/ memanfaatkan blogspot dalam proses publikasi profil, informasi dan kegiatan di Kelurahan Tangkerang Selatan, sehingga nantinya kebutuhan informasi dari masyarakat luas dapat tersedia dengan lebih mudah, cepat, dan jelas diterima.

\section{Waktu Dan Tempat Pelaksanaan}

Kegiatan ini dilaksanakan di Kantor Lurah Tangkerang Selatan pada tanggal 27 Agustus 2018. Peserta yang terlibat sebanyak 15 orang yang terdiri dari pegawai kelurahan dan mahasiswa yang membantu dalam pelaksanaan pelatihan

\section{Metode Pelaksanaan Kegiatan}

Pelaksanaan kegiatan pengabdian kepada masyarakat di Kantor Lurah Tangkerang Selatan Pekanbaru meliputi persiapan, pelaksanaan pengabdian dan evaluasi. Kegiatan tersebut dapat dilihat pada table berikut ini: 
Tabel 1. Tahapan Pelaksanaan Kegiatan

\begin{tabular}{|c|c|c|}
\hline $\begin{array}{l}\mathbf{N} \\
\mathbf{0}\end{array}$ & Tahapan & Kegiatan \\
\hline 1 & Persiapan & $\begin{array}{l}\text { - Koordinasi teknis } \\
\text { di lapangan } \\
\text { - Merumuskan } \\
\text { permasalahan- } \\
\text { permasalahan yang } \\
\text { dihadapi oleh pihak } \\
\text { kelurahan dalam } \\
\text { mengoptimalisasi } \\
\text { potensi layanan } \\
\text { informasi } \\
\text { - Meyiapkan materi } \\
\text { pelatihan, alat-alat } \\
\text { dan bahan-bahan } \\
\text { yang diperlukan } \\
\text { untuk kegiatan } \\
\text { pelatihan }\end{array}$ \\
\hline 2 & $\begin{array}{l}\text { Pelaksana } \\
\text { an }\end{array}$ & $\begin{array}{l}\text { - Penyampaian } \\
\text { Materi Web blog/ } \\
\text { Blogspot sebagai } \\
\text { media publikasi } \\
\text { profil } \\
\text { - Pelatihan } \\
\text { penggunaan } \\
\text { aplikasi Blogspot }\end{array}$ \\
\hline 3 & Evaluasi & $\begin{array}{l}\text { - Evaluasi hasil kerja } \\
\text { untuk mengetahui } \\
\text { kendala selama } \\
\text { pelatihan }\end{array}$ \\
\hline
\end{tabular}

\section{HASIL DAN PEMBAHASAN}

Upaya pengabdian kepada masyarakat telah dilakukan berupa pelatihan dengan berbagai materi khususnya menyangkut penggunaan Blogspot sebagai media publikasi profil. Semua kegiatan dapat berjalan sesuai dengan jadwal acara yang telah disusun sebelumnya.

Tindakan dalam kegiatan ini berupa implementasi program. Kegiatankegiatan yang dilakukan dalam implementasi program adalah sebagai berikut.

1. Memberikan pengenalan kepada guru-guru terkait penggunaan Blogspot dan pelatihan penggunaan
Blogspot sebagai media publikasi profil yang dapat diterapkan di Kelurahan Tangkerang Selatan Pekanbaru.

2. Meningkatkan pengetahuan dan keterampilan para pegawai kelurahan tentang pembuatan, penggunaan serta optimaliasi penggunaan blogspot sebagai media publikasi profil melalui pemberian pelatihan.

3. Mendemonstrasikan penggunaan blogspot sebagai media publikasi profil yang telah dibuat dari hasil pelatihan.

\section{Pelaksanaan Kegiatan}

Kegiatan pengabdian yang dilaksanakan pada pegawai kelurahan Tangkerang Selatan telah berlangsung dengan baik. Hal ini terlihat dari sambutan positif dan antusiasme dalam melaksanakan pelatihan dengan baik. Pihak kelurahan berharap pelaksanaan kegiatan dapat dilakukan secara kontinu untuk membantu meningkatkan kualitas pegawai terhadap penggunaan teknologi dalam kegiatan administrasi.

\section{SIMPULAN}

Berdasarkan kegiatan pengabdian masyarakat yang telah dilakukan di Kantor Lurah Tangkerang Selatan Pekanbaru, hasil yang dicapai adalah sebagai berikut:

a. Bertambahnya pengetahuan pegawai kelurahan tentang pemanfaatan Blogspot sebagai media publikasi profil guna mengenalkan profil wilayah maupun penyampaian informasi ke masyarakat luas.

b. Terciptanya website profil sebagai media publikasi online.

Dari hasil pelaksanaan kegiatan pengabdian masyarakat dapat disampaikan beberapa saran berikut:

a. Diharapkan pihak kelurahan dapat menunjuk salahsatu pegawai sebagai admin dari website profil yang dibangun 
b. Diharapakan agar para admin kelurahan dapat selalu memperbaharui konten pada website profil agar tujuan penyampaian informasi yang efektif dan efisien dapat terwujud dengan baik.

\section{UCAPAN TERIMA KASIH}

Ucapan terimakasih disampaikan kepada

- Kantor Lurah Tangkerang Selatan Pekanbaru yang telah memfasilitasi kegiatan ini.

- Seluruh Peserta kegiatan yang merupakan para pegawai di lingkungan Kelurahan Tangkerang Selatan yang begitu antusias dalam mengikuti kegiatan ini.

\section{DAFTAR PUSTAKA}

[1] Suteja, B.R., Sarapung, J.A \& Handaya, W.B.T. (2008). Memasuki Dunia Elearning, Bandung: Penerbit Informatika.

[2] Whitten, J.L, Bentley, L.D., Diitmen, K.C. (2004). System Analysis and Design Methods, Indianapolis: McGraw-Hill Education.

[3] Peranginangin, Kasimin (2006). Aplikasi WebLog dengan PHP dan MySql, Yogyakarta: Penerbit Andi Offset.

[4] Soni, S; Hafid, A; Hayami, R., Fatma, Y; Apri Wenando, F., Al Amien, J; \& Fuad, Evans ; Unik, Mitra ; Mukhtar, Harun; Hasanuddin, H; (2018). Optimalisasi Pemanfaatan Google Classroom Sebagai Media Pembelajaran di SMK Negeri 1 Bangkinang. Jurnal Pengabdian Untuk Mu NegeRI, 2(Mei 2018), 17-20.

[5] Yanuarsih, Sri dan Yunita Suryani Suryani. Aplikasi Web, Surabaya: Kasafani.

[6] Harahap, Sofyan Syafri. 2009. Langkah-Langkah Pembuatan
Web, Jakarta: Raja Grafindo Persada.

[7] Nurhadi dan Agus Gerad. 2003. Pengertian Pembelajaran, Yogyakarta: Grafindo Persada.

[8] Amien, J. A., Sunanto, , Soni, S., Mualfah, D. B., Fuad, E., \& Wenando, F. A. (2018). Pelatihan cara teknik pengutipan dan cara menghindari tindakan plagiat bagi guru SMK Muhammadiyah 3 Pekanbaru. Jurnal Pengabdian Untuk Mu NegeRI, 2(2), 40-43. 